\title{
Association between vascular endothelial growth factor gene polymorphisms and the risk and prognosis of renal cell carcinoma: A systematic review and meta-analysis
}

\author{
Jingyuan Tang ${ }^{1,2, *}$, Zhiqiang Qin ${ }^{1, *}$, Xiao Li $^{3, *}$, Peng Han ${ }^{1}$, Feng Wang ${ }^{4}$, Chengdi \\ Yang ${ }^{1}$, Ran Li ${ }^{1}$, Kunpeng Wang ${ }^{1,5}$, Min Tang ${ }^{1}$, Wei Wang ${ }^{1}$, Qiang Lv ${ }^{1}$ and Wei Zhang ${ }^{1}$ \\ ${ }^{1}$ Department of Urology, The First Affiliated Hospital of Nanjing Medical University, Nanjing, 210009, China \\ ${ }^{2}$ Department of Urology, Wuxi Second People's Hospital, Nanjing Medical University, Wuxi, 214002, China \\ ${ }^{3}$ Department of Urologic Surgery, The Affiliated Cancer Hospital of Jiangsu Province of Nanjing Medical University, Nanjing, \\ 210029, China \\ ${ }^{4}$ Department of Radiation Oncology, The First Affiliated Hospital of Nanjing Medical University, Nanjing, 210009, China \\ ${ }^{5}$ Department of Urology, The First People's Hospital of Lianyungang City, Lianyungang, 222002, China \\ *These authors have contributed equally to this work \\ Correspondence to: Wei Zhang, email: zhangwei_urology@163.com \\ Qiang Lv, email: doctorlvqiang@sina.com
}

Keywords: VEGF polymorphisms, renal cell carcinoma, risk, prognosis, meta-analysis

Received: October 12, $2016 \quad$ Accepted: April 03, $2017 \quad$ Published: April 20, 2017

Copyright: Tang et al. This is an open-access article distributed under the terms of the Creative Commons Attribution License 3.0 (CC BY 3.0), which permits unrestricted use, distribution, and reproduction in any medium, provided the original author and source are credited.

\section{ABSTRACT}

The aim of the meta-analysis was to clarify the associations between vascular endothelial growth factor (VEGF) polymorphisms and the risk and prognosis of renal cell carcinoma (RCC). A meta-analysis was performed by searching the databases PubMed, EMBASE and Web of Science for the relevant available studies until August 1st, 2016, and fourteen studies met the inclusion criteria. The pooled odds ratios (ORs) with $95 \%$ confidence intervals (CIs) were calculated to evaluate the strength of such associations. Besides, the pooled hazard ratios (HRs) with $95 \%$ CIs were used to evaluate the overall survival (OS). Fixed- or random-effects models were conducted according to existence of heterogeneity. Publication bias was evaluated using Begg's funnel plots and Egger's regression test. Overall, this meta-analysis included a total of 8,275 patients, who had been accrued between November 2002 and September 2015. Meta-analysis indicated that $-2578 \mathrm{C} / \mathrm{A},+936 \mathrm{C} / \mathrm{T}$ and $+405 \mathrm{G} / \mathrm{C}$ polymorphisms in the VEGF gene correlated with elevated RCC risk, especially in Asian populations. Moreover, VEGF -1154G/A and -634C/G polymorphisms were found significantly associated with poor OS of RCC. Therefore, this meta-analysis revealed that VEGF $-2578 \mathrm{C} / \mathrm{A},+936 \mathrm{C} / \mathrm{T},+405 \mathrm{G} / \mathrm{C}$ polymorphisms were associated with an elevated susceptibility to RCC, indicating that these three polymorphisms might be risk factors for RCC, especially in Asian populations.

\section{INTRODUCTION}

Renal cell carcinoma (RCC) is the most common malignancy of the kidney, accounting for approximately $80 \%-85 \%$ of all renal tumors [1]. Until now, many influencing factors have been identified that might increase the risk of RCC, including tobacco smoking, hypertension and occupational exposures to chemicals $[2,3]$. However, even if many people are exposed to these risk factors, only a few of them develop RCC. This suggests that genetic factors may have a critical influence on the aetiology of RCC. Several studies have confirmed the role of genetic factors in the development of RCC $[4,5]$.

Angiogenesis is the formation of new blood vessels from endothelial precursors and it is one of the fundamental processes in carcinogenesis [6, 7]. It is 
well known that angiogenesis is correlated with tumor progression and metastasis [8]. Vascular endothelial growth factor (VEGF), known as a critical angiogenesis factor, could promote tumor development and progression both in vitro and in vivo experiments [9-11]. Meanwhile, tumor-induced angiogenesis and growth could be suppressed by inhibiting VEGF signaling [12, 13]. The gene encoding VEGF, which comprises a 14-kb coding region with 8 exons, is located at chromosome $6 \mathrm{p} 21.3$ [14]. There are many single nucleotide polymorphisms (SNPs) identified in the VEGF gene, which can alter the expression level of this gene and confer individual susceptibility to tumor $[15,16]$.

Compared to healthy renal tissue, the VEGF expression level is higher in RCC tissue [17]. Moreover, specific drugs targeting VEGF have shown clinical effcacy in the treatment of $\operatorname{RCC}[18,19]$. Therefore, VEGF polymorphisms may be associated with the progression and prognosis of RCC. Several SNPs, such as VEGF -2578C/A, $-1156 \mathrm{G} / \mathrm{A},+1612 \mathrm{G} / \mathrm{A},+936 \mathrm{C} / \mathrm{T}$, and $-634 \mathrm{G} / \mathrm{C}$, have been reported to be associated with cancer susceptibility, tumor growth and metastases in RCC patients [20-22]. However, because of the limited sample size, these studies showed the results remained inconclusive. Thus, we performed a systemic review and an updated meta-analysis including all eligible case-control studies to investigate whether VEGF polymorphisms were associated with the risk and prognosis of RCC.

\section{RESULTS}

\section{Studies characteristics}

According to the searching criteria, a total of related 232 articles through a primary search of databases and reference lists were initially identified. As a result, of these articles, 14 full-text studies met the inclusion criteria and were involved in the present meta-analysis for a more further evaluation, which had been accrued between November 2002 and September 2016 [21-34]. Besides, all studies suggested that the distribution of genotypes in the controls was consistent between HWE. The flowchart of literature search and selection procedure is shown in Figure 1. In this meta-analysis, all of the baseline characteristics of the studies associated with the risk and prognosis of RCC are comprehensively listed in Table 1 and Table 2. Among all the SNPs of the VEGF gene addressed, $-2578 \mathrm{C} / \mathrm{A},+936 \mathrm{C} / \mathrm{T},+1612 \mathrm{G} / \mathrm{A},-634 \mathrm{G} / \mathrm{C}$, $+460 \mathrm{~T} / \mathrm{C},+405 \mathrm{G} / \mathrm{C},-1154 \mathrm{G} / \mathrm{A}$ were the most common. Among these 14 enrolled studies, there were 10 studies based on Asian population and 4 studies conducted in Caucasians population.

\section{Quantitative synthesis results}

Overall, the strength of association between VEGF genetic polymorphisms and RCC risk was evaluated

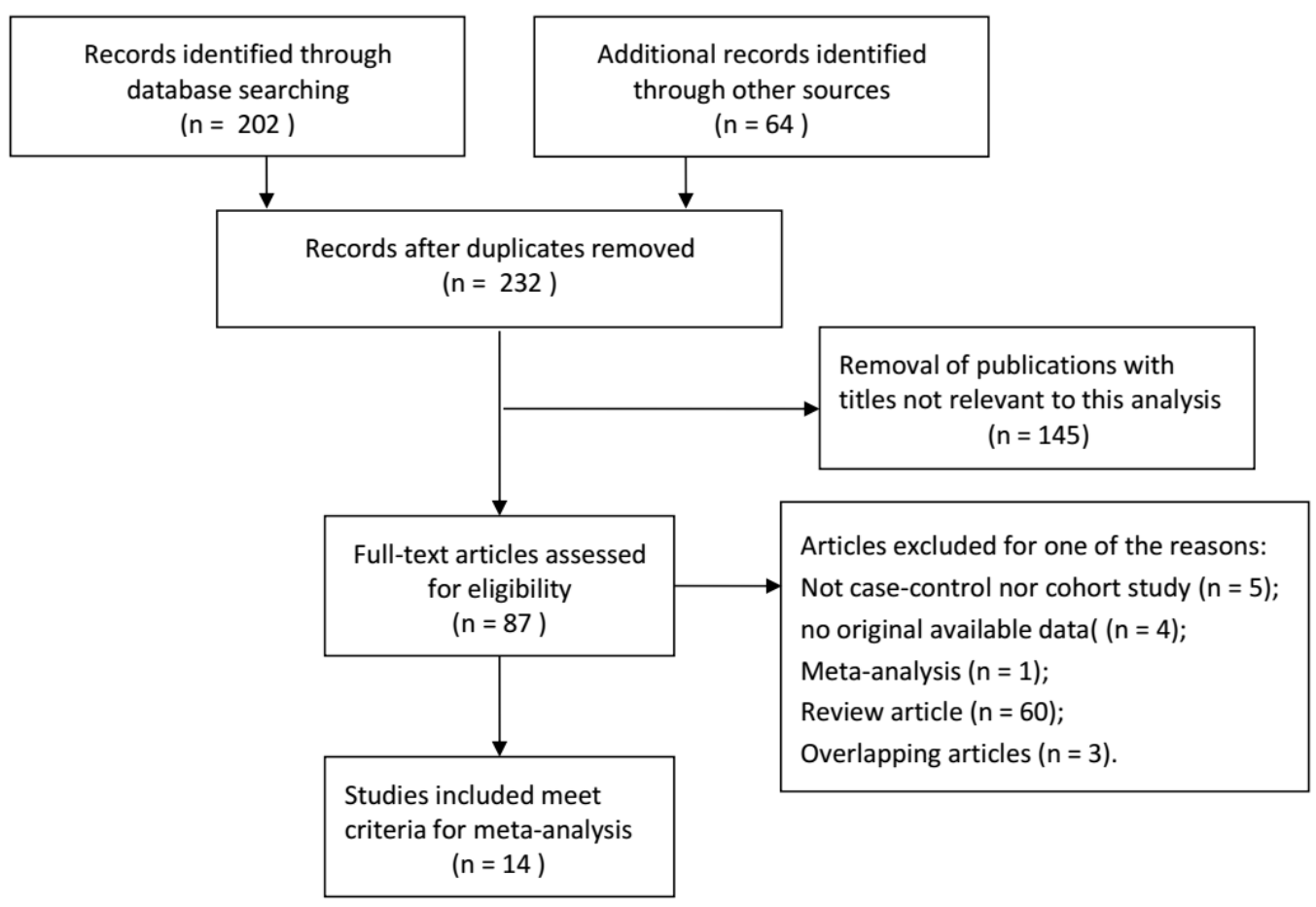

Figure 1: The flowchart of literature search and selection procedure. 
Table 1: Baseline characteristics of studies associated with the risk of RCC included in the meta-analysis

\begin{tabular}{|c|c|c|c|c|c|c|c|c|c|c|}
\hline Ref. & Year & Surname & Ethnicity & SOC & Genotyping & Cases & Controls & $\begin{array}{c}\text { Gene } \\
\text { polymorphism }\end{array}$ & NOS & HWE \\
\hline [26] & 2015 & Yang & Asian & HB & Taqman & 191 & 376 & $\begin{array}{c}-2578 \mathrm{C} / \mathrm{A},-1154 \mathrm{G} / \\
\mathrm{A},-634 \mathrm{G} / \mathrm{C} \\
+936 \mathrm{C} / \mathrm{T}\end{array}$ & 6 & $\mathrm{Y}$ \\
\hline [23] & 2015 & Shen & Asian & HB & PCR-RFLP & 360 & 360 & $\begin{array}{c}-2578 \mathrm{C} / \mathrm{A} \\
+1612 \mathrm{G} / \mathrm{A} \\
+936 \mathrm{C} / \mathrm{T},-634 \mathrm{G} / \mathrm{C}\end{array}$ & 5 & $\mathrm{Y}$ \\
\hline [24] & 2015 & Xian & Asian & $\mathrm{HB}$ & PCR-RFLP & 266 & 532 & $\begin{array}{c}-2578 \mathrm{C} / \mathrm{A} \\
+1612 \mathrm{G} / \mathrm{A} \\
+936 \mathrm{C} / \mathrm{T},-634 \mathrm{G} / \mathrm{C}\end{array}$ & 5 & Y \\
\hline [25] & 2015 & $\mathrm{Lu}$ & Asian & HB & PCR-RFLP & 412 & 824 & $\begin{array}{c}-2578 \mathrm{C} / \mathrm{A},+1612 \mathrm{G} / \\
\mathrm{A},+460 \mathrm{~T} / \mathrm{C} \\
+936 \mathrm{C} / \mathrm{T},-634 \mathrm{G} / \mathrm{C}\end{array}$ & 5 & Y \\
\hline$[27]$ & 2014 & Qin & Asian & $\mathrm{HB}$ & Taqman & 859 & 1004 & $+405 \mathrm{G} / \mathrm{C}$ & 7 & $\mathrm{Y}$ \\
\hline [28] & 2013 & Sáenz-López & Caucasian & HB & Taqman & 216 & 280 & $\begin{array}{c}-2578 \mathrm{C} / \mathrm{A} \\
+460 \mathrm{~T} / \mathrm{C},+405 \mathrm{G} / \mathrm{C} \\
+936 \mathrm{C} / \mathrm{T}\end{array}$ & 6 & $\mathrm{Y}$ \\
\hline [29] & 2011 & Ajaz & Asian & HB & PCR-RFLP & 143 & 106 & $-2578 \mathrm{C} / \mathrm{A},+936 \mathrm{C} / \mathrm{T}$ & 5 & $\mathrm{Y}$ \\
\hline [30] & 2010 & Bruyère & Caucasian & HB & PCR-RFLP & 51 & 202 & $\begin{array}{l}+460 \mathrm{~T} / \mathrm{C},+405 \mathrm{G} / \mathrm{C} \\
+936 \mathrm{C} / \mathrm{T},-1154 \mathrm{G} / \mathrm{A}\end{array}$ & 5 & $\mathrm{Y}$ \\
\hline$[31]$ & 2009 & Ricketts & Caucasian & $\mathrm{HB}$ & PCR-RFLP & 317 & 295 & $-1154 \mathrm{G} / \mathrm{A}$ & 6 & $\mathrm{Y}$ \\
\hline$[32]$ & 2002 & Abe & Asian & $\mathrm{HB}$ & PCR-RFLP & 145 & 145 & $\begin{array}{l}+936 \mathrm{C} / \mathrm{T} \\
+1612 \mathrm{G} / \mathrm{A}\end{array}$ & 5 & $\mathrm{Y}$ \\
\hline
\end{tabular}

SOC: source of control; HB: hospital-based; HWE: Hardy-Weinberg equilibrium.

NOS: Newcastle-Ottawa Scale

Table 2: Baseline characteristics of studies associated with the prognosis of RCC included in the meta-analysis

\begin{tabular}{cccccccccc}
\hline Ref. Year & Surname & Ethnicity & Genotyping & Cases & $\begin{array}{c}\text { Gene } \\
\text { polymorphism }\end{array}$ & $\begin{array}{c}\text { Survival } \\
\text { analysis }\end{array}$ & $\begin{array}{c}\text { Source of } \\
\text { HR }\end{array}$ & $\begin{array}{c}\text { Max } \\
\text { months for } \\
\text { follow-up }\end{array}$ \\
Nos \\
[33]
\end{tabular}

HR: hazard ratio; OS: overall survival; NOS: Newcastle-Ottawa Scale. 
by the pooled ORs with 95\% CIs based on five genetic comparison models. A summary of all the meta-analysis results for the seven studied VEGF polymorphisms and RCC susceptibility is provided in Table 3. In addition, the results of subgroup analysis by ethnicity is shown in Supplementary Table 1.

\section{$-2578 \mathrm{C} / \mathrm{A}$ and $\mathrm{RCC}$ risk}

The combined results of all analyses showed that the pooled OR of these six studies was $1.30(95 \% \mathrm{CI}$ : 1.18-1.43) for allele model, 1.60 (95\% CI: 1.31-1.96) for homozygote model, 1.24 (95\% CI: 1.08-1.43) for heterozygote model, 1.31 (95\% CI: 1.15-1.50) for dominant model and 1.39 (95\% CI: 1.16-1.67) for recessive model, which indicated a strong association between VEGF $-2578 \mathrm{C} / \mathrm{A}$ mutation and RCC susceptibility. Furthermore, subgroups analysis by ethnicity was performed to establish the effects of heterogeneity on the results. In the subgroup analysis by ethnicity, the results were significant in Asian populations rather than Caucasians population in all genetic models, including allele model: pooled $\mathrm{OR}=1.33,95 \% \mathrm{CI}$ : 1.20-1.47; homozygote model: pooled $\mathrm{OR}=1.67,95 \% \mathrm{CI}$ : 1.34-2.07; heterozygote model: pooled $\mathrm{OR}=1.30,95 \% \mathrm{CI}$ : 1.01-1.67; dominant model: pooled $\mathrm{OR}=1.36,95 \% \mathrm{CI}$ : 1.07-1.73; recessive model: pooled $\mathrm{OR}=1.44,95 \%$ CI: 1.18 1.76 (Figure 2).

\section{$+936 \mathrm{C} / \mathrm{T}$ and $\mathrm{RCC}$ risk}

Significant differences were found between VEGF $+936 \mathrm{C} / \mathrm{T}$ polymorphism and RCC risk using allele model: pooled $\mathrm{OR}=1.16,95 \% \mathrm{CI}$ : 1.05-1.29; homozygote model: pooled $\mathrm{OR}=1.33,95 \% \mathrm{CI}: 1.08-1.65$; dominant model: pooled $\mathrm{OR}=1.16,95 \% \mathrm{CI}: 1.02-1.33$; recessive model: pooled $\mathrm{OR}=1.25,95 \% \mathrm{CI}: 1.02-1.52$. When the studies were stratified by ethnicity, significant differences were observed in Asian population in those models (allele model: pooled $\mathrm{OR}=1.18,95 \% \mathrm{CI}$ : $1.06-1.32$; homozygote model: pooled $\mathrm{OR}=1.37,95 \%$ CI: $1.11-1.70$; dominant model: pooled $\mathrm{OR}=1.18,95 \% \mathrm{CI}$ : $1.02-1.36$; recessive model: pooled $\mathrm{OR}=1.27,95 \% \mathrm{CI}: 1.04-1.56$ ), but, no significant results were detected in Caucasian population (Figure 3).

\section{$+1612 \mathrm{G} / \mathrm{A}$ and RCC risk}

In the present meta-analysis, the results demonstrated that the VEGF $+1612 \mathrm{G} /$ A polymorphism was significant correlated with RCC only in allele model (pooled OR $=1.08,95 \%$ CI: 1.00-1.17) and homozygote model (pooled OR $=1.33,95 \%$ CI: 1.02-1.74) (Figure 4).

\section{$-634 \mathrm{G} / \mathrm{C}$ and $\mathrm{RCC}$ risk}

No statistically significant association between VEGF $-634 \mathrm{G} / \mathrm{C}$ polymorphism and RCC susceptibility was assessed in all genetic comparison models and the stratified analysis by ethnicity.

\section{$+460 \mathrm{~T} / \mathrm{C}$ and $\mathrm{RCC}$ risk}

The pooled analysis has shown that the VEGF $+460 \mathrm{~T} / \mathrm{C}$ polymorphism was not significantly associated with RCC susceptibility in all five genetic models. However, when the studies were stratified by ethnicity, the positive result was detected in Asian population for allele model (pooled OR $=1.32,95 \%$ CI: 1.10-1.58), dominant model (pooled OR $=1.33,95 \%$ CI: 1.05-1.69) and recessive model (pooled OR $=1.35,95 \%$ CI: 1.01 1.81) (Figure 5).

\section{$+405 \mathrm{G} / \mathrm{C}$ and $\mathrm{RCC}$ risk}

The combined results of all analyses showed that the pooled OR of these studies was 1.18 (95\% CI: 1.05-1.33) for allele model, 1.35 (95\% CI: 1.06-1.72) for homozygote model and 1.25 (95\% CI: 1.05-1.48) for heterozygote model and 1.27(95\% CI: 1.08-1.49) for dominant model, which indicated a significant association between VEGF $+405 \mathrm{G} / \mathrm{C}$ polymorphism and RCC risk. In addition, when the studies were stratified by ethnicity, the significant results were found only in Asian populations in allele model: pooled $\mathrm{OR}=1.23,95 \%$ CI: $1.08-1.41$; homozygote model: pooled $\mathrm{OR}=1.46,95 \% \mathrm{CI}: 1.10-1.91$; heterozygote model: pooled $\mathrm{OR}=1.30,95 \%$ CI: $1.06-1.60$; dominant model: pooled $\mathrm{OR}=1.34,95 \% \mathrm{CI}$ : 1.11-1.62 (Figure 6).

\section{-1154G/A and RCC risk}

In all genetic models, no significant differences was found in VEGF -1154G/A mutation for RCC risk.

\section{VEGF genetic polymorphisms and prognosis of RCC}

Because of the large number of studies evaluating the relationship of three individual VEGF polymorphisms (VEGF -2578C/A, -1154G/A and -634C/G; individual details in Table 2) and the prognosis of RCC, meta-analyses were performed separately on these polymorphisms. As a result, VEGF -1154G/A and -634C/ $\mathrm{G}$ polymorphisms were found significantly associated with poor OS in homozygote model $(-1154 \mathrm{G} / \mathrm{A}$ : $\mathrm{HR}=2.30$, $95 \% \mathrm{CI}=1.25-4.24 ;-634 \mathrm{C} / \mathrm{G}: \mathrm{HR}=1.94,95 \% \mathrm{CI}=1.35$ 2.77). However, no significant differences was detected in VEGF $-2578 \mathrm{C} / \mathrm{A}$ polymorphism $(\mathrm{HR}=1.34,95 \% \mathrm{CI}=$ 0.96-1.88) (Figure 7).

\section{Sensitivity analysis}

Individual studies were consecutively omitted in the sensitivity analysis to detect the influence of each study on the pooled OR. The sensitivity analysis for the results of 
Table 3: Meta-analysis results for the seven studied polymorphisms and RCC risk

\begin{tabular}{|c|c|c|c|c|}
\hline \multirow[b]{2}{*}{ Genotype comparison } & \multirow[b]{2}{*}{ OR $[95 \% \mathrm{CI}]$} & \multicolumn{2}{|c|}{ Heterogeneity-test } & \multirow[b]{2}{*}{ Model } \\
\hline & & $\begin{array}{c}P \text { for } Q \\
\text { test }\end{array}$ & $\mathrm{I} 2(\%)$ & \\
\hline \multicolumn{5}{|c|}{ VEGF -2578C/A (1588 cases, 2470 controls) } \\
\hline A vs C (Allele model) & $1.30[1.18,1.43]$ & 0.689 & 0 & Fixed \\
\hline AA vs CC (Homozygous model) & $1.60[1.31,1.96]$ & 0.430 & 0 & Fixed \\
\hline CA vs CC (Heterozygous model) & $1.24[1.08,1.43]$ & 0.062 & 52.4 & Fixed \\
\hline AA+CA vs CC (Dominant model) & $1.31[1.15,1.50]$ & 0.051 & 54.5 & Fixed \\
\hline AA vs CA+CC (Recessive model) & $1.39[1.16,1.67]$ & 0.626 & 0 & Fixed \\
\hline \multicolumn{5}{|c|}{ VEGF +936C/T (1636 cases, 2712 controls) } \\
\hline T vs C (Allele model) & $1.16[1.05,1.29]$ & 0.130 & 39.3 & Fixed \\
\hline TT vs CC (Homozygous model) & $1.33[1.08,1.65]$ & 0.236 & 25.3 & Fixed \\
\hline CT vs CC (Heterozygous model) & $1.13[0.97,1.30]$ & 0.246 & 23.9 & Fixed \\
\hline TT+CT vs CC (Dominant model) & $1.16[1.02,1.33]$ & 0.123 & 40.2 & Fixed \\
\hline TT vs CT+CC (Recessive model) & $1.25[1.02,1.52]$ & 0.478 & 0 & Fixed \\
\hline \multicolumn{5}{|c|}{ VEGF +1612G/A (1184 cases, 1862 controls) } \\
\hline A vs G (Allele model) & $1.08[1.00,1.17]$ & 0.639 & 0 & Fixed \\
\hline AA vs GG (Homozygous model) & $1.33[1.02,1.74]$ & 0.527 & 0 & Fixed \\
\hline GA vs GG (Heterozygous model) & $1.09[0.93,1.27]$ & 0.919 & 0 & Fixed \\
\hline AA+GA vs GG (Dominant model) & $1.12[0.96,1.30]$ & 0.760 & 0 & Fixed \\
\hline AA vs GA+GG (Recessive model) & $1.27[0.99,1.64]$ & 0.558 & 0 & Fixed \\
\hline \multicolumn{5}{|c|}{ VEGF -634G/C (1229 cases, 2092 controls) } \\
\hline C vs G (Allele model) & $1.11[1.00,1.23]$ & 0.882 & 0 & Fixed \\
\hline CC vs GG (Homozygous model) & $1.22[0.99,1.51]$ & 0.964 & 0 & Fixed \\
\hline GC vs GG (Heterozygous model) & $1.13[0.96,1.32]$ & 0.998 & 0 & Fixed \\
\hline CC+GC vs GG (Dominant model) & $1.15[0.99,1.33]$ & 0.994 & 0 & Fixed \\
\hline CC vs GC+GG (Recessive model) & $1.14[0.94,1.38]$ & 0.961 & 0 & Fixed \\
\hline \multicolumn{5}{|c|}{ VEGF +460T/C (677 cases, 1299 controls) } \\
\hline C vs T (Allele model) & $0.92[0.58,1.46]$ & 0.000 & 87.9 & Random \\
\hline CC vs TT (Homozygous model) & $0.88[0.38,2.01]$ & 0.006 & 80.6 & Random \\
\hline TC vs TT (Heterozygous model) & $1.12[0.89,1.41]$ & 0.235 & 31 & Fixed \\
\hline CC+TC vs TT (Dominant model) & $0.98[0.61,1.58]$ & 0.017 & 75.5 & Random \\
\hline CC vs TC+TT (Recessive model) & $1.10[0.87,1.39]$ & 0.011 & 77.9 & Random \\
\hline \multicolumn{5}{|c|}{ VEGF +405 G/C (1086 cases, 1460 controls) } \\
\hline C vs G (Allele model) & $1.18[1.05,1.33]$ & 0.113 & 54.1 & Fixed \\
\hline CC vs GG (Homozygous model) & $1.35[1.06,1.72]$ & 0.125 & 51.8 & Fixed \\
\hline GC vs GG (Heterozygous model) & $1.25[1.05,1.48]$ & 0.407 & 0 & Fixed \\
\hline CC+GC vs GG (Dominant model) & $1.27[1.08,1.49]$ & 0.191 & 39.5 & Fixed \\
\hline CC vs GC+GG (Recessive model) & $1.06[0.84,1.33]$ & 0.628 & 0 & Fixed \\
\hline
\end{tabular}




\begin{tabular}{lcccc}
\hline & OR [95\% CI] & \multicolumn{2}{c}{ Heterogeneity-test } & Podel \\
Genotype comparison & & test & I2(\%) & Mod \\
\hline VEGF -1154G/A (564 cases, 892 controls) & & & & \\
A vs G (Allele model) & $1.04[0.88,1.24]$ & 0.228 & 32.3 & Fixed \\
AA vs GG (Homozygous model) & $1.07[0.73,1.57]$ & 0.330 & 9.7 & Fixed \\
GA vs GG (Heterozygous model) & $1.06[0.84,1.35]$ & 0.392 & 0 & Fixed \\
AA+GA vs GG (Dominant model) & $1.06[0.84,1.32]$ & 0.266 & 24.4 & Fixed \\
AA vs GA+GG (Recessive model) & $1.04[0.72,1.51]$ & 0.493 & 0 & Fixed \\
\hline
\end{tabular}

VEGF genetic polymorphisms and RCC risk demonstrated that the obtained results were statistically robust and no individual study affected the pooled OR significantly.

\section{Publication bias}

The Begg's funnel plot and Egger's test were applied to assess the publication bias of the literature in the meta-analysis. As illustrated in Figure 8, the shapes of funnel plots showed no evidence of obviously asymmetrical, indicating no evidence of publication bias in dominant model $(-2578 \mathrm{C} / \mathrm{A}, P=0.573 ;+936 \mathrm{C} / \mathrm{T}$, $P=0.652 ;+405 \mathrm{G} / \mathrm{C}, P=0.602)$. Moreover, no publication bias was found in test for $-2578 \mathrm{C} / \mathrm{A},-1154 \mathrm{G} / \mathrm{A},-634 \mathrm{C} / \mathrm{G}$ on survival. Therefore, our results were reliable according to the overall findings.

\section{DISCUSSION}

As a multifunctional cytokine, VEGF plays a crucial role in the regulation of angiogenesis which has attracted attention because of its involvement in the development of some common cancers $[8,35]$. VEGF could promote endothelial cell proliferation and the development of new blood vessels [36]. The process of carcinogenesis might be accelerated when the VEGF gene expression was influenced by some functional gene variations. Moreover, the serum VEGF levels from cancer patients were significantly higher than those without signs of cancer [37]. There are several polymorphisms in the VEGF gene and previous studies have indicated many polymorphisms are correlated with various types of cancer including gastric, lung, prostate, breast and renal cancer [38-40]. VEGF gene polymorphisms could influence the susceptibility, tumor grade and OS of cancer [22, 41].

Renal cancer is one of the most common cancers, and it is a major clinical and societal problem in the world [1]. There is growing evidence that aberrations in VEGF contribute to RCC [42]. Moreover, RCC accounts for $2-3 \%$ of human cancer and is mainly attributed to the frequent mutations of the von HippelLindau (VHL) tumor suppressor gene [43]. During the past several years, many case-control studies published have assessed the associations of VEGF polymorphisms with the risk of renal cancer, but the findings were inconsistent [23-26]. A case-control study in a Chinese population indicated that individuals with the AA genotype and A allele of $-2578 \mathrm{C} /$ A significantly increased the risk of RCC, when compared with the CC genotype [24]. However, another case-control study showed -2578C/A polymorphism did not appear to exert a significant influence on the risk of RCC [28].

A recent meta-analysis suggested that VEGF $+936 \mathrm{C} / \mathrm{T},+1612 \mathrm{G} / \mathrm{A},-1154 \mathrm{G} / \mathrm{A},-2549 \mathrm{I} / \mathrm{D},-460 \mathrm{~T} / \mathrm{C}$ and $+405 \mathrm{G} / \mathrm{C}$ gene polymorphisms were not associated with the risk of RCC, while $-2578 \mathrm{C} / \mathrm{A}$ gene polymorphism might increase the risk under specific genetic models [44]. However, the author only reviewed 5 studies. Another meta-analysis showed that the $+936 \mathrm{C} / \mathrm{T}$ and $-2578 \mathrm{C} / \mathrm{A}$ polymorphisms of VEGF were associated with an increased risk for renal cell carcinoma [45]. However, none of the two meta-analysis found the significant association between VEGF $+405 \mathrm{G} / \mathrm{C}$ gene polymorphisms and RCC risk due to limited published studies, and the latter meta-analysis did not perform the subgroup analysis. Thus, the conclusion in the previous studies was still inaccurate. In addition, those authors failed to assess the predictive value of VEGF polymorphisms in the prognosis of RCC. In recent years, more studies have evaluated the connection between VEGF polymorphisms and the risk and prognosis of RCC [23-27]. To the best of our knowledge, the sample size in the meta-analysis is larger than any individual study, making more precise and robust results. Thus, the present meta-analysis aimed to provide a more powerful and reliable conclusion about the relationship between VEGF genetic polymorphisms and RCC susceptibility.

This meta-analysis of individual patient data showed that VEGF $-2578 \mathrm{C} / \mathrm{A},+936 \mathrm{C} / \mathrm{T},+405 \mathrm{G} / \mathrm{C}$ polymorphisms 


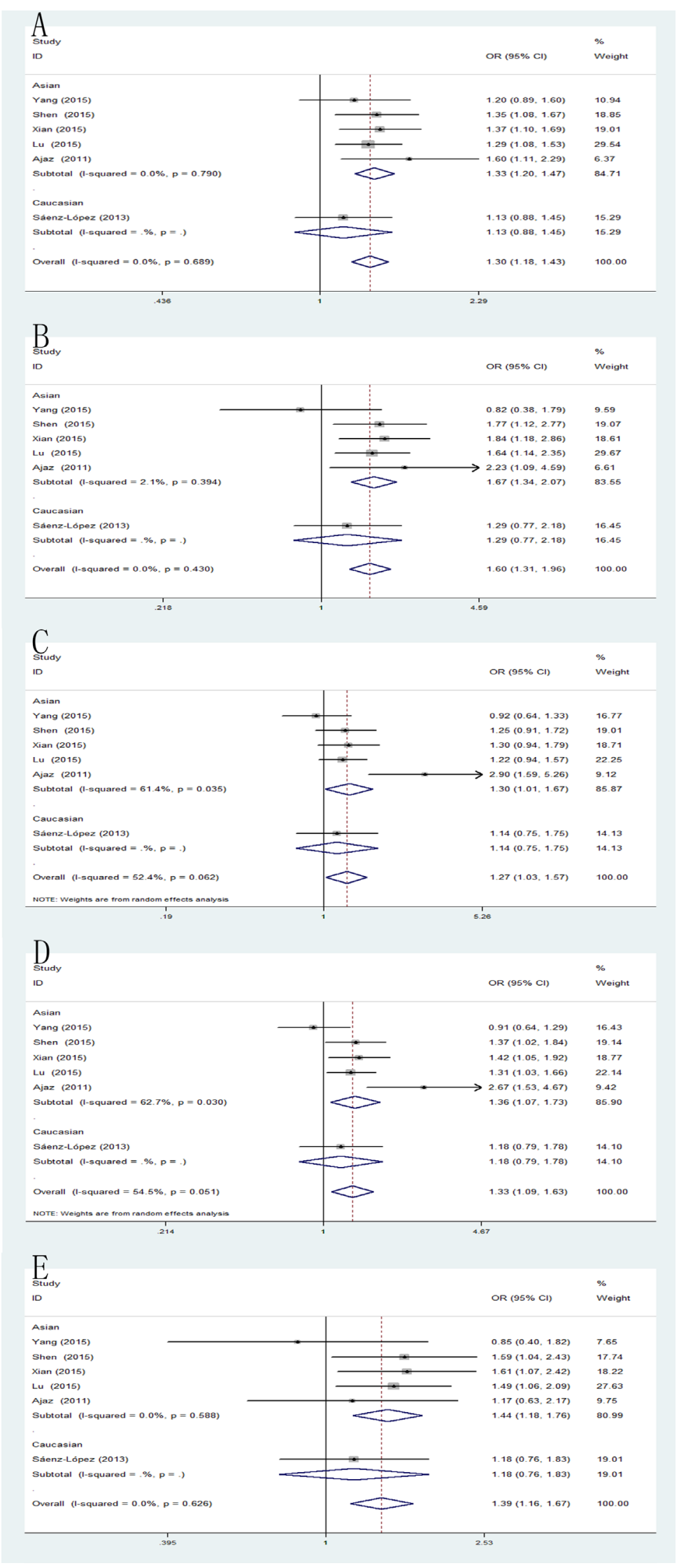

Figure 2: Forest plot of the association between the -2578C/A polymorphism and RCC risk. (A) allele model; (B) homozygote model; (C) heterozygote model; (D) dominant model; (E) recessive model. 


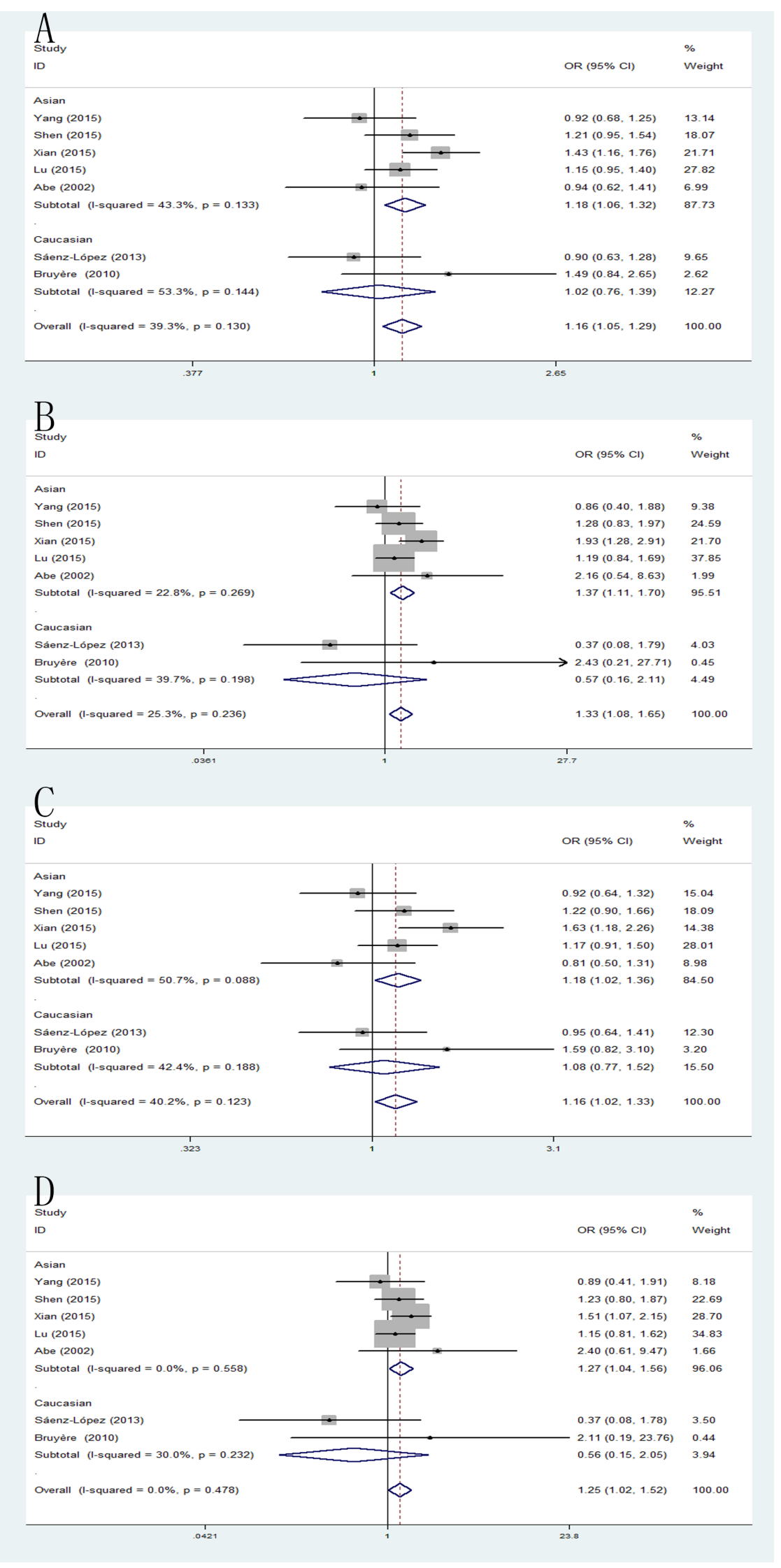

Figure 3: Forest plot of the association between the $+936 \mathrm{C} / \mathrm{A}$ polymorphism and RCC risk. (A) allele model; (B) homozygote model; (C) dominant model; (D) recessive model. 
correlated with an elevated risk of RCC, indicating that these polymorphisms might be risk factors for RCC, especially in Asian populations. However, no statistically significant association was found between $-634 \mathrm{G} / \mathrm{C}$, $-1154 \mathrm{G} / \mathrm{A},+1612 \mathrm{G} / \mathrm{A}$ polymorphisms and RCC risk.
Interestingly, VEGF $+460 \mathrm{~T} / \mathrm{C}$ polymorphism was found significantly associated with susceptibility of RCC, only in Asian populations. Though the exact mechanism of ethnic differences was unknown, a possible reason could be genetic drift and natural selection [46].

\section{A}

Study

ID
$\%$

$\operatorname{RR}(95 \% \mathrm{Cl})$

Weight

\begin{tabular}{|c|c|c|}
\hline Shen (2015) & $1.10(0.95,1.28)$ & 26.61 \\
\hline Xian (2015) & $1.13(0.97,1.31)$ & 25.70 \\
\hline Lu (2015) & $1.06(0.95,1.19)$ & 43.06 \\
\hline Abe (2002) & $0.85(0.55,1.31)$ & 4.63 \\
\hline Overall (l-squared $=0.0 \%, p=0.639)$ & $1.08(1.00,1.17)$ & 100.00 \\
\hline
\end{tabular}

B

Study

ID
$\%$

OR $(95 \% \mathrm{Cl}) \quad$ Weight

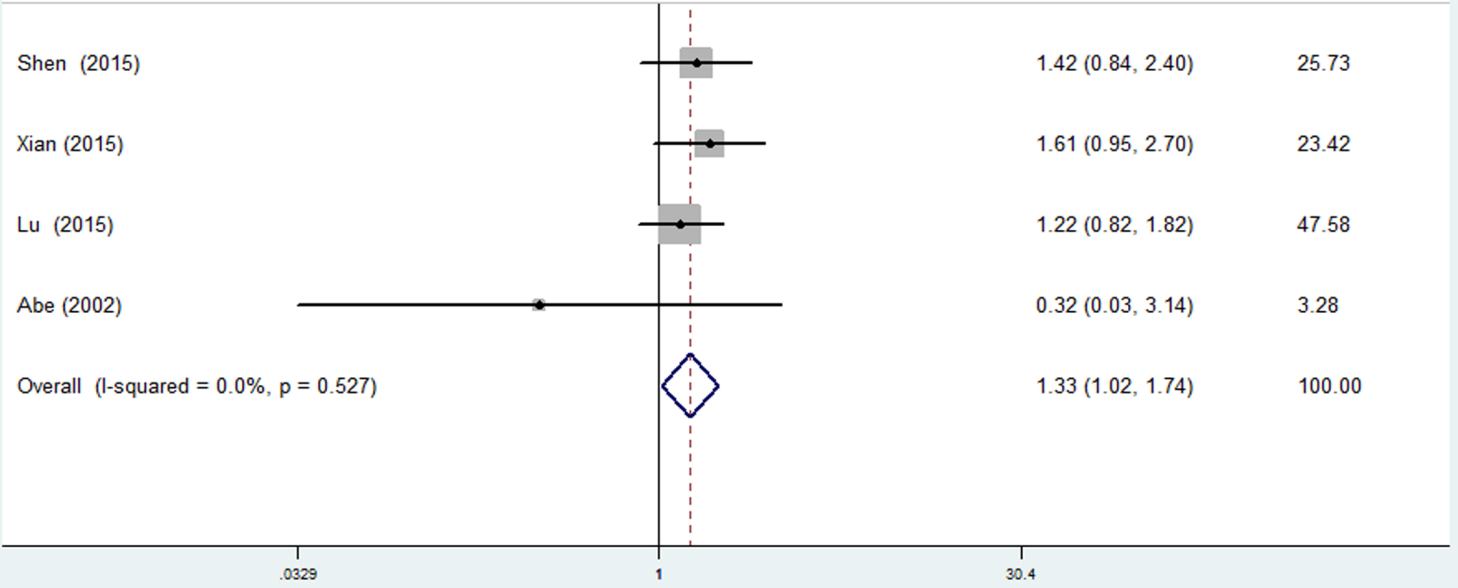

Figure 4: Forest plot of the association between the $+1612 \mathrm{C} / \mathrm{A}$ polymorphism and RCC risk. (A) allele model; (B) dominant model. 


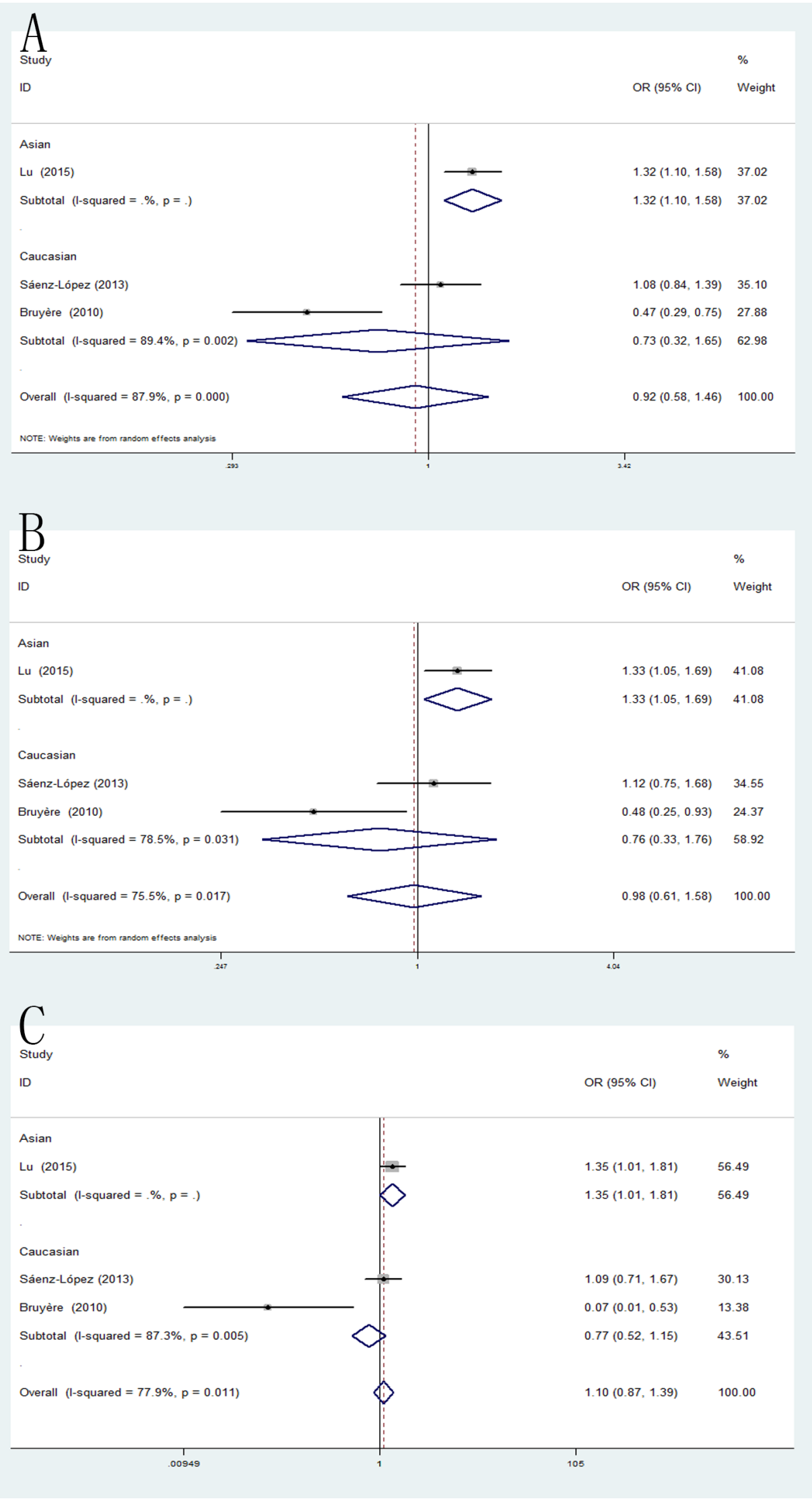

Figure 5: Forest plot of the association between the $+460 \mathrm{C} / \mathrm{A}$ polymorphism and RCC risk. (A) allele model; (B) homozygote model; (C) recessive model. 


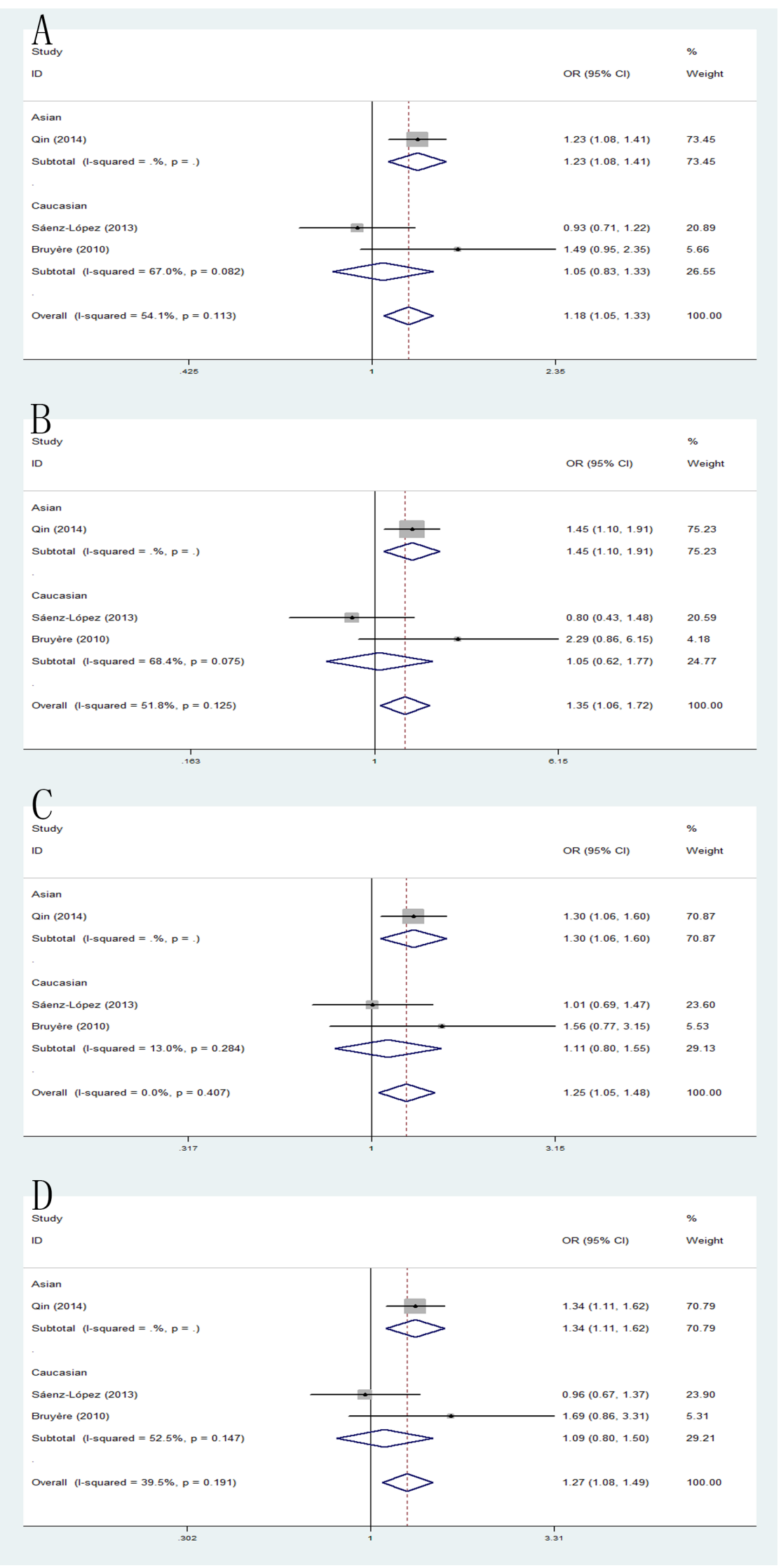

Figure 6: Forest plot of the association between the $+405 \mathrm{C} / \mathrm{A}$ polymorphism and $\mathrm{RCC}$ risk. (A) allele model; (B) homozygote model; (C) heterozygote model; (D) dominant model. 


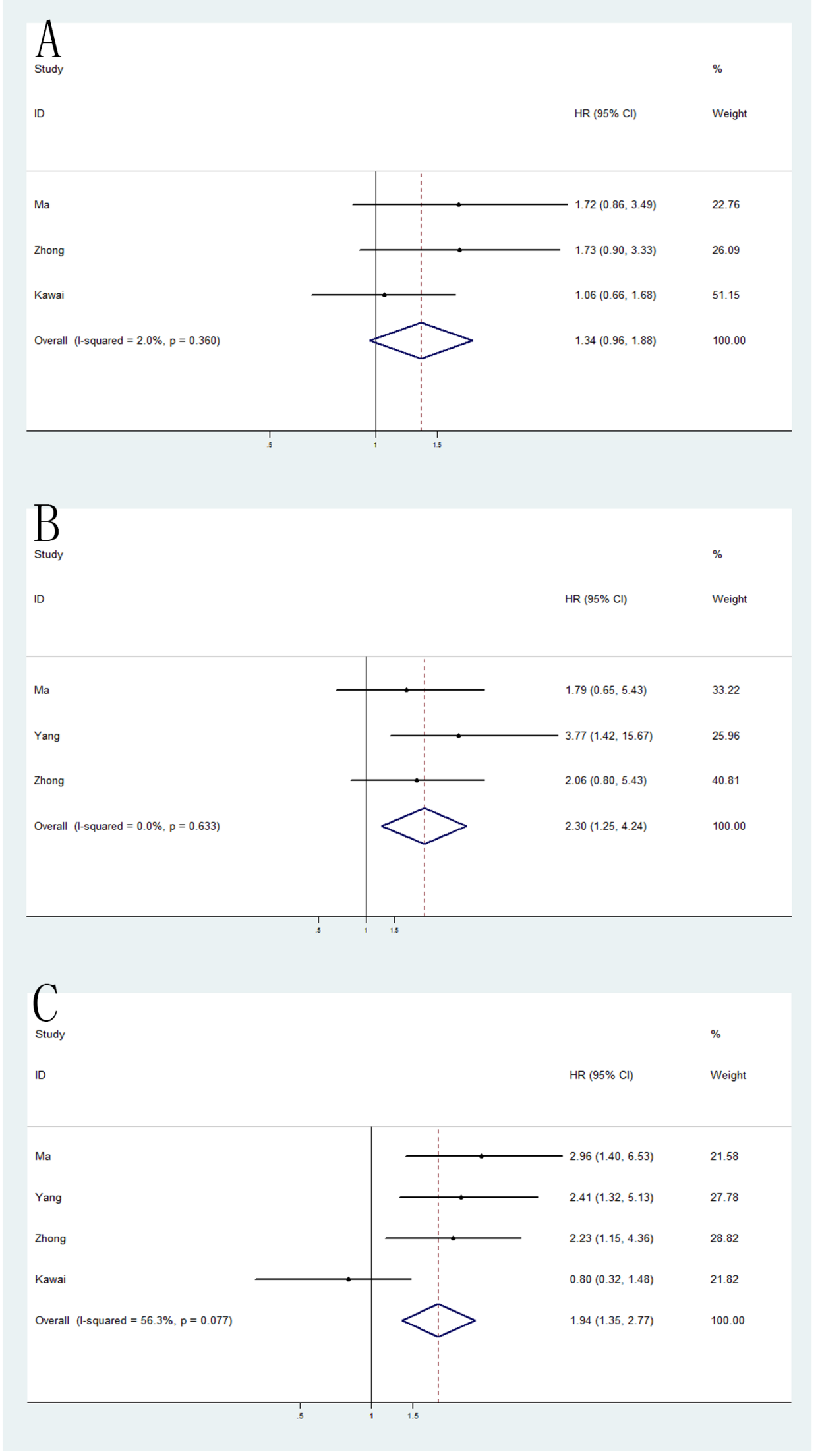

Figure 7: Forest plot of the association between $-2578 \mathrm{C} / \mathrm{A},-1154 \mathrm{G} / \mathrm{A}$ and $-634 \mathrm{C} / \mathrm{G}$ polymorphism and the overall survival of RCC. 

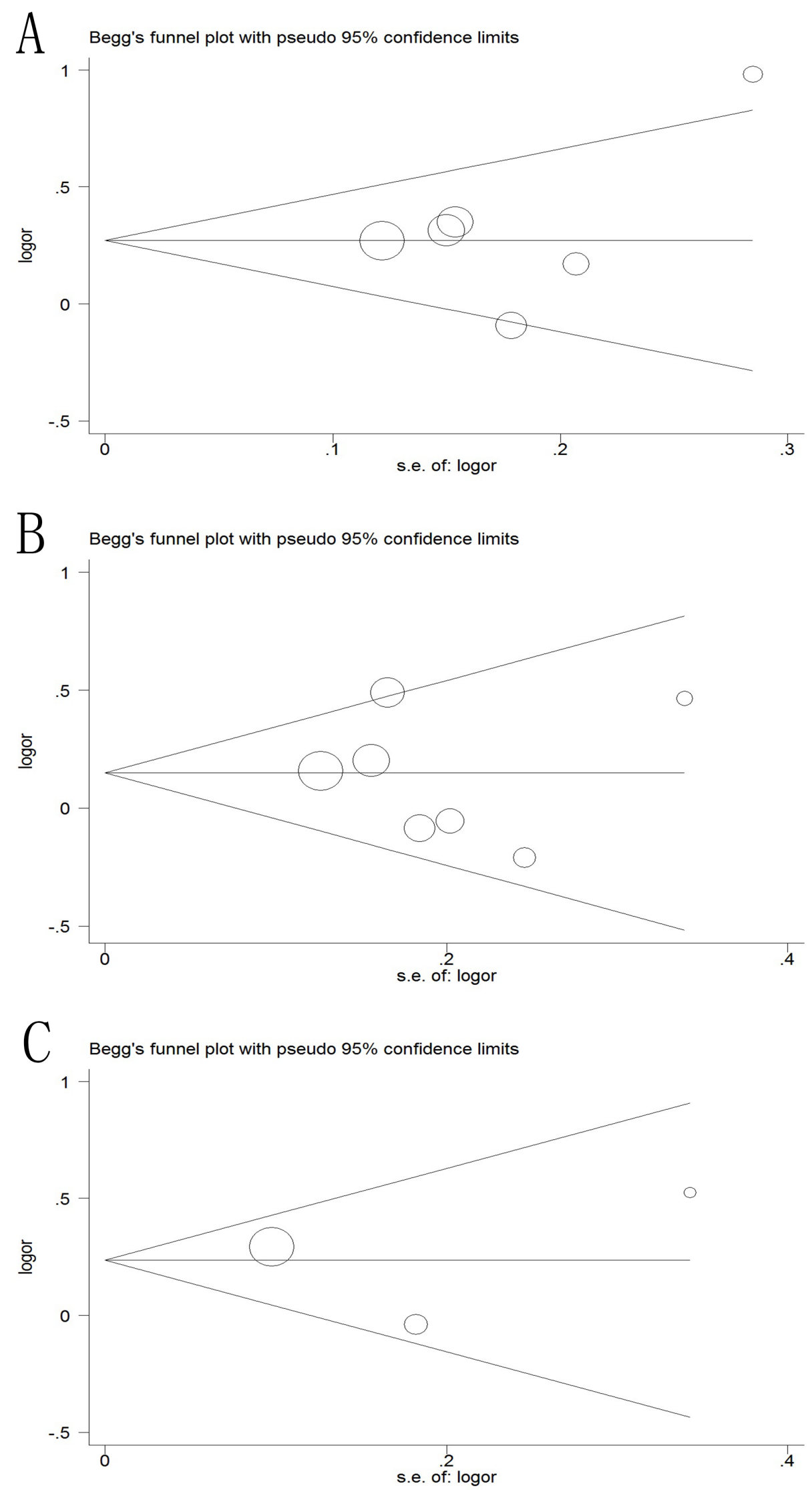

Figure 8: Begg's funnel plot of publication bias test in the dominant model. (A) $-2578 \mathrm{C} / \mathrm{A}$ polymorphism; (B) $+936 \mathrm{C} / \mathrm{A}$ polymorphism; (C) +405 C/A polymorphism. 
To investigate the association between VEGF variants and the prognosis of RCC, 4 independent case-control studies were included with a total of $1,191 \mathrm{RCC}$ cases, the results revealed that significant differences were found in VEGF -1154G/A and -634C/ $\mathrm{G}$ polymorphisms. Nevertheless, VEGF $-2578 \mathrm{C} / \mathrm{A}$ mutation was not significantly associated with poor OS. The discrepancy is likely that $-2578 \mathrm{C} / \mathrm{A}$ is involved in $\mathrm{RCC}$ initiation, and VEGF $-1154 \mathrm{G} / \mathrm{A}$ and $-634 \mathrm{C} / \mathrm{G}$ are involved in progression or treatment response, or tumor heterogeneity [47].

To a certain extent, some limitations should also be emphasized when interpreting the data. (1) Most populations included in this meta-analysis were Asian and Caucasian ethnicity, and more populations from other ethnicities will be required in the future research. (2) The number of included studies in some subgroups was relatively small, with limited statistical power to investigate the real association. More studies by standardized unbiased methods are required, which can offer more detailed individual data of high quality. (3) Adjusted estimates could not be performed in our metaanalysis without enough data for the adjustment by other RCC covariates such as age, life-style and so on. (4) No available data assessing the association between VEGF genetic polymorphisms and the OS of RCC was obtained in some included studies. Therefore, further high-quality researches in RCC prognosis might be performed to draw more accuracy results in subsequent years.

\section{CONCLUSION}

In summary, the results of the current metaanalysis indicated that $\mathrm{VEGF}-2578 \mathrm{C} / \mathrm{A},+936 \mathrm{C} / \mathrm{T}$, $+405 \mathrm{G} / \mathrm{C}$ polymorphisms were associated with an elevated susceptibility to RCC, indicating that these three polymorphisms might be risk factors for RCC, especially in Asian populations. Moreover, VEGF -1154G/A and $-634 \mathrm{C} / \mathrm{G}$ polymorphisms were found significantly associated with poor prognosis of RCC and might become a predicted biomarker in the future. Additional highquality and multicenter studies with larger sample sizes are needed to confirm our findings in subsequent articles.

\section{MATERIALS AND METHODS}

According to the Preferred Reporting Items for Systematic Reviews and Meta-Analyses (PRISMA), we performed a comprehensive search based on PubMed, EMBASE and Web of Science obtain relevant studies published until August 1st, 2016. The combination of the following search items and $\mathrm{MeSH}$ terms were utilized: "vascular endothelial growth factor" or "VEGF", "polymorphism" or "mutation", "variants" and "renal cell carcinoma" or "kidney cancer". Other potentially eligible literature were collected by manually searching from relevant reviews and the references of original studies included for the meta-analysis. Besides, all remaining articles were checked to prevent overlapping datasets. Furthermore, because the data was from previously published studies, ethical approval and informed consent were not required.

Eligible studies were selected according to the following inclusion criteria: (1) Independent casecontrol or cohort studies; (2) The association between VEGF variants and the risk and the prognosis of RCC; (3) Inclusion of adequate data on frequency of genotypes including ORs and the their 95\% CIs. In addition, the study did not meet the inclusion criteria was excluded.

\section{Data extraction}

According to the above the inclusion criteria, two investigators (Tang JY and Qin ZQ) independently extracted available data from the eligible studies identified, and any disagreements were resolved by discussion with a third reviewer until a consensus was reached. All the extracted information were recorded in a standardized form and the extracted elements included: year of publication, first author's last name, ethnicity, source of controls, genotyping assay, the number of cases and controls, the number of VEGF gene polymorphisms carriers and non-carriers respectively, and the results of the Hardy-Weinberg equilibrium (HWE) test.

\section{Quality assessment}

The quality of the studies was assessed using the validated Newcastle-Ottawa Scale (NOS) for nonrandomized studies. A study can be awarded a maximum of one star for each point within the selection and exposure categories, and a maximum of two stars can be given for comparability. We considered studies with scores of more than 5 as high-quality studies and only high-quality studies were included in our meta-analysis.

\section{Statistical analysis}

The strength of association between VEGF mutations and RCC susceptibility was evaluated by the pooled odds ratios (ORs) with 95\% confidence intervals (CIs) based on five genetic comparison models: allele model, homozygous model, heterozygous model, dominant model and recessive model. For the primary assessment of the association between VEGF polymorphisms and the overall survival (OS) of RCC, we used the overall hazard ratios (HRs). The goodness-of-fit chi-square test was adopted to assess HWE in controls and $\mathrm{P}<0.05$ was regarded as significant disequilibrium. The pooled ORs were calculated either with fixedeffects model (a Mantel-Haenszel method) or with the random-effects model (a DerSimonian-Laird method) according to the $P$ values of study heterogeneities. If 
there was no indication of substantial heterogeneity, the fixed-effects model would be conducted. Otherwise, the random effects model was selected to perform this metaanalysis. Then subgroup analysis according to ethnicity was further carried out to explore the potential sources of heterogeneity. To examine the stability and reliability of the overall meta-analysis results, sensitivity analysis was performed by excluding one single study one by one and recalculating their ORs. In addition, Begg's funnel plots and Egger's linear regression test were employed to search for publication bias between the studies, and $P$ values were deemed as a significantly selective bias when less than 0.05. STATA software (version 12.0; StataCorp LP, College Station, TX) was utilized to deal with all above statistical analyses.

\section{ACKNOWLEDGMENTS}

This work has been supported by the National Natural Science Funding of China (No. 81370781, 81670608, 81600514).

\section{CONFLICTS OF INTEREST}

We declare that we have no conflicts of interest.

\section{Ethical statements}

None declared.

\section{REFERENCES}

1. Siegel RL, Miller KD, Jemal A. Cancer statistics, 2016. CA Cancer J Clin. 2016; 66:7-30.

2. Karami S, Yanik EL, Moore LE, Pfeiffer RM, Copeland G, Gonsalves L, Hernandez BY, Lynch CF, Pawlish K, Engels EA. Risk of Renal Cell Carcinoma Among Kidney Transplant Recipients in the United States. Am J Transplant. 2016; 16:3479-3489.

3. Chow WH, Devesa SS. Contemporary epidemiology of renal cell cancer. Cancer J. 2008; 14:288-301.

4. Zhao H, Leppert JT, Peehl DM. A Protective Role for Androgen Receptor in Clear Cell Renal Cell Carcinoma Based on Mining TCGA Data. PLoS One. 2016; 11:e146505.

5. Yap NY, Rajandram R, Ng KL, Pailoor J, Fadzli A, Gobe GC. Genetic and Chromosomal Aberrations and Their Clinical Significance in Renal Neoplasms. Biomed Res Int. 2015; 2015:476508.

6. D'Alessio A, Proietti G, Lama G, Biamonte F, Lauriola L, Moscato U, Vescovi A, Mangiola A, Angelucci C, Sica G. Analysis of angiogenesis related factors in glioblastoma, peritumoral tissue and their derived cancer stem cells. Oncotarget. 2016; 7:78541-78556. doi: 10.18632/ oncotarget.12398.
7. Su SC, Hsieh MJ, Yang WE, Chung WH, Reiter RJ, Yang SF. Cancer metastasis: mechanisms of inhibition by melatonin. J Pineal Res. 2017; 62.

8. Yao M, Brummer G, Acevedo D, Cheng N. Cytokine Regulation of Metastasis and Tumorigenicity. Adv Cancer Res. 2016; 132:265-367.

9. Morales A, Morimoto S, Vilchis F, Taniyama N, Bautista CJ, Robles C, Bargallo E. Molecular expression of vascular endothelial growth factor, prokineticin receptor-1 and other biomarkers in infiltrating canalicular carcinoma of the breast. Oncol Lett. 2016; 12:2720-2727.

10. Yancopoulos GD, Davis S, Gale NW, Rudge JS, Wiegand SJ, Holash J. Vascular-specific growth factors and blood vessel formation. Nature. 2000; 407:242-248.

11. Kondo T, Tsunematsu T, Yamada A, Arakaki R, Saito M, Otsuka K, Kujiraoka S, Ushio A, Kurosawa M, Kudo $\mathrm{Y}$, Ishimaru N. Acceleration of tumor growth due to dysfunction in M1 macrophages and enhanced angiogenesis in an animal model of autoimmune disease. Lab Invest. 2016; 96:468-480.

12. Hicklin DJ, Ellis LM. Role of the vascular endothelial growth factor pathway in tumor growth and angiogenesis. J Clin Oncol. 2005; 23:1011-1027.

13. Andersen S, Donnem T, Al-Shibli K, Al-Saad S, Stenvold $\mathrm{H}$, Busund LT, Bremnes RM. Prognostic impacts of angiopoietins in NSCLC tumor cells and stroma: VEGF-A impact is strongly associated with Ang-2. PLoS One. 2011; 6:e19773.

14. Giacca M, Zacchigna S. VEGF gene therapy: therapeutic angiogenesis in the clinic and beyond. Gene Ther. 2012; 19:622-629.

15. Chen N, Ma CN, Zhao M, Zhang YJ. Role of VEGF gene polymorphisms in the clinical outcome of non-small cell lung cancer. Genet Mol Res. 2015; 14:16006-16011.

16. Hu GL, Ma G, Ming JH. Impact of common SNPs in VEGF gene on the susceptibility of osteosarcoma. Genet Mol Res. 2015; 14:14561-14566.

17. Rivet J, Mourah S, Murata H, Mounier N, Pisonero H, Mongiat-Artus P, Teillac P, Calvo F, Janin A, Dosquet C. VEGF and VEGFR-1 are coexpressed by epithelial and stromal cells of renal cell carcinoma. Cancer. 2008; 112:433-442.

18. Han KS, Raven PA, Frees S, Gust K, Fazli L, Ettinger $\mathrm{S}$, Hong SJ, Kollmannsberger C, Gleave ME, So AI. Cellular Adaptation to VEGF-Targeted Antiangiogenic Therapy Induces Evasive Resistance by Overproduction of Alternative Endothelial Cell Growth Factors in Renal Cell Carcinoma. Neoplasia. 2015; 17:805-816.

19. Zahoor H, Rini BI. Emerging growth factor receptor antagonists for the treatment of renal cell carcinoma. Expert Opin Emerg Drugs. 2016; 21:431-440.

20. Xian W, Zheng $\mathrm{H}, \mathrm{Wu}$ WJ. Predictive value of vascular endothelial growth factor polymorphisms on the risk of renal cell carcinomas. Genet Mol Res. 2015; 14:7634-7642. 
21. Zhong W, Wang X, Pan B, Su Z. Association of vascular endothelial growth factor polymorphisms with clinical outcome of renal cell carcinoma patients. Tumour Biol. 2014; 35:9839-9845.

22. Kawai Y, Sakano S, Korenaga Y, Eguchi S, Naito K. Associations of Single Nucleotide Polymorphisms in the Vascular Endothelial Growth Factor Gene with the Characteristics and Prognosis of Renal Cell Carcinomas. Eur Urol. 2007; 52:1147-1155.

23. Shen BL, Qu QS, Miao SZ, Zhang YX. Association between SNPs in vascular endothelial growth factor polymorphisms and risk of renal cell carcinoma: a case-control study. Genet Mol Res. 2015; 14:11119-11125.

24. Xian $\mathrm{W}$, Zheng $\mathrm{H}, \mathrm{Wu}$ WJ. Predictive value of vascular endothelial growth factor polymorphisms on the risk of renal cell carcinomas. Genet Mol Res. 2015; 14:7634-7642.

25. Lu G, Dong Y, Zhang Q, Jiao L, Yang S, Shen B. Predictive value of vascular endothelial growth factor polymorphisms on the risk of renal cell carcinomas: a case-control study. Tumour Biol. 2015; 36:8645-8652.

26. Yang S, Huang C, Shiue H, Huang S, Pu Y, Chen W, Lin Y, Hsueh Y. Joint Effect of Urinary Total Arsenic Level and VEGF-A Genetic Polymorphisms on the Recurrence of Renal Cell Carcinoma. PLoS One. 2015; 10:e145410.

27. Qin C, Chen J, Li J, Ju X, Zhang S, Cao Q, Han Z, Li P, Shao P, Wang M, Zhang Z, Gu M, Zhang W, et al. Variants in angiogenesis-related genes and the risk of clear cell renal cell carcinoma. Mutagenesis. 2014; 29:419-425.

28. Sáenz-López P, Vazquez F, Cozar JM, Carretero R, Garrido F, Ruiz-Cabello F. VEGF polymorphisms are not associated with an increased risk of developing renal cell carcinoma in Spanish population. Hum Immunol. 2013; 74:98-103.

29. Ajaz S, Khaliq S, Abid A, Hassan AS, Hashmi A, Sultan G, Mohsin R, Mubarrak M, Naqvi SAA, Rizvi SA, Mehdi SQ. Association of a Single-Nucleotide Polymorphism in the Promoter Region of the VEGF Gene with the Risk of Renal Cell Carcinoma. Genet Test Mol Biomarkers. 2011; 15:653-657.

30. Bruyère F, Hovens CM, Marson M, Faivre D'Arcier B, Costello AJ, Watier H, Linassier C, Ohresser M. VEGF Polymorphisms are Associated With an Increasing Risk of Developing Renal Cell Carcinoma. The Journal of Urology. 2010; 184:1273-1278.

31. Ricketts C, Zeegers MP, Lubinski J, Maher ER. Analysis of germline variants in CDH1, IGFBP3, MMP1, MMP3, STK15 and VEGF in familial and sporadic renal cell carcinoma. PLoS One. 2009; 4:e6037.

32. Abe A, Sato K, Habuchi T, Wang L, Li Z, Tsuchiya N, Ohyama C, Satoh S, Ogawa O, Kato T. Single nucleotide polymorphisms in the $3^{\prime}$ untranslated region of vascular endothelial growth factor gene in Japanese population with or without renal cell carcinoma. Tohoku J Exp Med. 2002; 198:181-190.
33. Ma N, Li LW, Cheng JL. Predictive value of vascular endothelial growth factor polymorphisms on the clinical outcome of renal cell carcinoma patients. Oncol Lett. 2015; 9:651-656.

34. Yang YQ, Chen J. Predictive role of vascular endothelial growth factor polymorphisms in the survival of renal cell carcinoma patients. Genet Mol Res. 2014; 13:5011-5017.

35. Goertz L, Schneider SW, Desch A, Mayer FT, Koett J, Nowak K, Karampinis I, Bohlmann MK, Umansky V, Bauer AT. Heparins that block VEGF-A-mediated von Willebrand factor fiber generation are potent inhibitors of hematogenous but not lymphatic metastasis. Oncotarget. 2016; 7:68527-68545. doi: 10.18632/oncotarget.11832.

36. Bautch VL. VEGF-directed blood vessel patterning: from cells to organism. Cold Spring Harb Perspect Med. 2012; 2:a6452.

37. Kondo S, Asano M, Matsuo K, Ohmori I, Suzuki H. Vascular endothelial growth factor/vascular permeability factor is detectable in the sera of tumor-bearing mice and cancer patients. Biochim Biophys Acta. 1994; 1221:211-214.

38. Mohammadi M, Bazrafshani MR, Day PJ, Ollier WE. Vascular endothelial growth factor production is regulated by gene polymorphisms. Iran J Immunol. 2009; 6:119-129.

39. Liu C, Zhou X, Gao F, Qi Z, Zhang Z, Guo Y. Correlation of genetic polymorphism of vascular endothelial growth factor gene with susceptibility to lung cancer. Cancer Gene Ther. 2015; 22:312-316.

40. VanCleave TT, Moore JH, Benford ML, Brock GN, Kalbfleisch T, Baumgartner RN, Lillard JJ, Kittles RA, Kidd LC. Interaction among variant vascular endothelial growth factor (VEGF) and its receptor in relation to prostate cancer risk. Prostate. 2010; 70:341-352.

41. Bhaskari J, Premalata CS, Shilpa V, Rahul B, Pallavi VR, Ramesh G, Krishnamoorthy L. Vascular endothelial growth factor polymorphisms and a synchronized examination of plasma and tissue expression in epithelial ovarian cancers. Tumour Biol. 2016; 37:1017-1023.

42. Badal SA, Aiken WD, Chin SN. Molecular targets and angiogenesis in renal cell carcinoma, a multi-target approach: mini review. Curr Drug Targets. 2016 May 2. [Epub ahead of print].

43. Sato Y, Yoshizato T, Shiraishi Y, Maekawa S, Okuno Y, Kamura T, Shimamura T, Sato-Otsubo A, Nagae G, Suzuki H, Nagata Y, Yoshida K, Kon A, et al. Integrated molecular analysis of clear-cell renal cell carcinoma. Nat Genet. 2013; 45:860-867.

44. Zhang Y, Li S, Xiao HQ, Hu ZX, Xu YC, Huang Q. Vascular endothelial growth factor gene polymorphisms and renal cell carcinoma: A systematic review and metaanalysis. Oncol Lett. 2013; 6:1068-1078.

45. Gong M, Dong W, Shi Z, Qiu S, Yuan R. Vascular endothelial growth factor gene polymorphisms and the risk of renal cell carcinoma: Evidence from eight case-control 
studies. Oncotarget. 2017; 8:8447-8458. doi: 10.18632/ oncotarget. 14263.

46. Thomas DC, Witte JS. Point: population stratification: a problem for case-control studies of candidate-gene associations? Cancer Epidemiol Biomarkers Prev. 2002; 11:505-512.
47. Hsieh JJ, Manley BJ, Khan N, Gao J, Carlo MI, Cheng $\mathrm{EH}$. Overcome tumor heterogeneity-imposed therapeutic barriers through convergent genomic biomarker discovery: A braided cancer river model of kidney cancer. Semin Cell Dev Biol. 2017; 64:98-106. 